\title{
A CONTRIBUIÇÃO DA SALA DE AULA INVERTIDA E OS IMPACTOS NA EDUCAÇÃO E NA SOCIEDADE
}

\author{
Carla Natiele Bassalobre Debia ${ }^{1}$ \\ Helton Adriano de Souza²
}

DEBIA, C. N. B.; SOUZA, H. A. de. A contribuição da sala de aula invertida e os impactos na educação e na sociedade. EDUCERE - Revista da Educação, Umuarama, v. 19, n. 2, p. 433-453, jul./dez. 2019.

RESUMO: O presente artigo visou a analisar como ocorre o processo de ensino aprendizagem por meio da sala de aula invertida. Primeiramente, buscou-se descrever as mudanças ocorridas na sociedade com a intenção de justificar o uso dessa tecnologia em sala de aula. Para tanto, a metodologia utilizada se caracterizou como revisão de literatura de natureza básica, classificada como pesquisa exploratória. A pesquisa demonstrou que no Brasil, ainda existem poucas pesquisas sobre a temática e, portanto, a aplicabilidade desse método ainda não ocorre em grande escala. Porém, percebeu-se que ele gera resultados positivos, mesmo enfrentando desafios na adaptação do educador e do educando. Ainda, observou-se que a sala de aula invertida é capaz de mesclar o ensino presencial e o ensino a distância, fazendo emergir novos meios de interação, aprendizagem e possibilitando o desenvolvimento do senso crítico dos alunos. $\mathrm{O}$ paradigma que findou a análise permeia a barreira cultural frente às novas tecnologias educacionais e a acessibilidade dela no âmbito educacional brasileiro.

PALAVRAS-CHAVE: Ensino; Aprendizagem; Sala de aula invertida.

DOI: 10.25110/educere.v19i2.2019.7150

${ }^{1}$ Especialista em docência e gestão do ensino superior pela Universidade Paranaense/UNIPAR, especialista em gestão empresarial pela Universidade Paranaense/UNIPAR e responsável técnica tutora mediadora dos cursos de pós-graduação do núcleo de gestão e negócios, modalidade EAD da Universidade Paranaense/UNIPAR. E-mail: carla.natiele@hotmail.com

${ }^{2}$ Mestre em educação pela UNIOESTE/PR, na linha de história e histografia da educação, professor titular da Universidade Paranaense/UNIPAR e professor da rede pública de ensino do Estado do Paraná. E-mail: heltonadriano@prof.unipar.br 


\section{CONTRIBUTION OF INVERTED CLASSROOM AND IMPACTS ON EDUCATION AND SOCIETY}

ABSTRACT: The following article aimed at showing how the learning process through an inverted classroom takes place. Firstly, it attempts to describe all the changes occurred in society with the intention of justifying the use of such technology in the classroom. For such, it used a bibliographical review with a basic nature as methodology, classified as an exploratory research. The research has shown that in Brazil, there are still few studies on the topic, thus, the applicability of this method is not widespread yet. However, it has been observed that it can generate positive results, despite facing challenges in both teacher and student adaptation. It has been observed, that the inverted classroom is able to mix the on-site education with distance learning, providing new interaction and learning means, enabling the development of the students' critical sense. The paradigm which guides the analysis goes through the cultural barrier facing new education technologies and their accessibility in the Brazilian educational background.

KEYWORDS: Teaching; Learning; Flipped classroom.

\section{LA CONTRIBUCIÓN DEL AULA INVERTIDA Y LOS IMPACTOS EN LA EDUCACIÓN Y EN LA SOCIEDAD}

RESUMEN: El presente artículo tiene como objetivo analizar cómo ocurre el proceso de enseñanza aprendizaje a través del aula invertida. En primer lugar, se buscó describir los cambios ocurridos en la sociedad con la intención de justificar el uso de esa tecnología en el aula. Para ello, la metodología utilizada se caracterizó como revisión de literatura de naturaleza básica, clasificada como investigación exploratoria. La investigación demostró que en Brasil, todavía existen pocas investigaciones sobre la temática $\mathrm{y}$, por lo tanto, la aplicabilidad de ese método aún no ocurre a gran escala. Sin embargo, se percibió que él genera resultados positivos, aunque enfrentando desafíos en la adaptación del educador y del educando. Se observó que el aula invertida es capaz de mezclar la enseñanza presencial y la enseñanza a distancia, haciendo surgir nuevos medios de interacción, aprendizaje y posibilitando el desarrollo del sentido crítico 
de los estudiantes. El paradigma que concluyó el análisis permea la barrera cultural frente a las nuevas tecnologías educativas y la accesibilidad de ella en el ámbito educativo brasileño.

PALABRAS CLAVE: Enseñanza; Aprendizaje; Aula invertida.

\section{INTRODUÇÃO}

Com o passar dos anos, a sociedade transformou seus conceitos, cultura e seu modo de viver em geral, e assim, com todas essas mudanças ocorridas, nascem um novo modo de pensar e agir.

Entende-se que a educação e a sociedade estão mutuamente interligadas, portanto, compreende-se que, algumas mudanças sofridas pela segunda, ocasionam alterações nas estruturas escolares, com o objetivo de adaptação e utilização das novas tecnologias disponíveis.

"O advento da sociedade pós-industrial, em meados do século 20 , teve como esfera principal a tecnologia, que possibilitou o rápido crescimento do setor de serviços, em oposição ao setor manufatureiro" (FAVA, 2012, p. 1). Sendo assim, todo esse crescimento e disponibilidade de tecnologias forjou uma nova forma de pensar e agir coletivamente.

Para Fava (2012, p. 01), "se na sociedade industrial o cérebro foi deixado de lado, a sociedade digital requer que as pessoas pensem, que desenvolvam a habilidade de buscar a essência, separar o que é importante e útil daquilo que é descartável".

As mudanças ocorridas na educação se dão em partes pelo advento tecnológico, que facilita a aprendizagem e de outro lado pela necessidade imposta pela sociedade de se aprender e especializar-se cada dia mais.

Segundo Souza (2014), os desafios ocasionados pela geração digital e pelas novas tecnologias juntam-se à inquietações antigas, como a evasão e inadimplência. A adaptação a uma, porém, pode ser a opção para resolver a outra.

Atualmente, vivencia-se a era do conhecimento e das informações disponíveis em vários tipos de plataformas, que por sua vez, são de fácil acesso à grande parcela da sociedade, entende-se então, que a educação sofreu ou sofre algum tipo de mudança, seja em sua estrutura curricular ou entre a relação aluno-professor. E é nesse contexto, que surgem métodos didático-pedagógicos como ensino hibrido, metodologias 
ativas e sala de aula invertida.

Dessa mudança ocorrida na sociedade, emanam os novos objetivos e tantas necessidades e, é na educação que a atual geração encontra os meios e ferramentas para um desenvolvimento holístico a fim de acompanhar as tendências de mercado. Uma geração que já nasce com o conhecimento nas mãos e que exige mais do que apenas conceitos para compreensão dos conteúdos, ou seja, indivíduos que necessitam de experiências que rompem com as estruturas das salas de aula tradicionais.

A tecnologia está modificando a educação, não exclusivamente na organização, escolha ou disponibilidade dos conteúdos, mas também na distribuição. Surgindo assim, a necessidade das instituições se adaptarem, para que não haja falhas perante aos novos conceitos da sociedade digital (FAVA, 2012). Diante dessa demanda de alunos, surge a necessidade de acrescentar a tecnologia disponível ao processo de aprendizagem. A essência educacional se manterá, porém, utilizará de novas ferramentas, para facilitar a transmissão do conhecimento.

Compreende-se que os professores estão utilizando todas as possibilidades existentes para gerar conhecimento satisfatório, considerando todos os avanços ocorridos na sociedade. Sendo assim, esse trabalho justifica-se de forma a fomentar e atualizar os questionamentos e debates quanto à educação e os seus métodos utilizados em sala de aula, onde o escolhido para essa análise foi a sala de aula invertida.

É nesse contexto que surge o tema desse trabalho, onde estudou-se a sala de aula invertida. Essa técnica permite que o professor disponibilize antecipadamente e por meio de plataformas digitais o conteúdo da disciplina ao aluno, para que assim o estudante tenha contato com o conteúdo antes mesmo de a aula acontecer. Assim, a intenção desse método é que o aluno obtenha informações sobre o conteúdo e no momento da aula o estudante tenha conhecimento prévio para que haja uma exposição das ideias estudadas anteriormente.

O estudo ainda verificou se esse método é eficaz frente às demandas educacionais ao englobar as tecnologias já existentes. Foi perquirido, por meio de revisão literária, a contribuição da sala de aula invertida para o processo de aprendizagem, fazendo uma junção entre as tecnologias disponíveis e a aprendizagem. 


\section{PRESSUPOSTOS TEÓRICO-METODOLÓGICOS}

Para realização dessa pesquisa, foi definido como objetivo geral estudar como ocorre o processo de ensino aprendizagem por meio da sala de aula invertida. E como objetivos específicos, descrever as mudanças reais da sociedade com a intenção de justificar o uso das tecnologias em sala de aula.

Tendo como finalidade, aprofundar os conhecimentos sobre metodologias educacionais, ou seja, a sala de aula invertida, o procedimento técnico do presente trabalho será a partir de pesquisa literária. Segundo Cervo, Bervian e Silva (2007, p. 60), "a pesquisa bibliográfica procura explicar um problema a partir de referências teóricas publicadas em artigos, livros, dissertações e teses".

Para obter maior familiaridade com o assunto acorremos às identificações das variáveis necessárias para melhor compreensão desse estudo, afinal, reiteramos nosso foco na pesquisa exploratória. De acordo com Köche (2015, p. 126), "o objetivo fundamental de uma pesquisa exploratória é o de descrever ou caracterizar a natureza das variáveis que se quer conhecer". Para tanto, as variáveis serão identificadas por meio de levantamento bibliográfico, analisando e compreendendo os debates e pesquisas de autores sobre sala de aula invertida, sua aplicabilidade e resultados.

Com o intuito de complementar a descrição do percurso da investigação, será utilizado a pesquisa básica que, por sua vez, “objetiva gerar conhecimentos novos, úteis para o avanço da Ciência, sem aplicação prática prevista. Envolve verdades e interesses universais" (GERHARDT; SILVEIRA, 2009, p. 34).

\section{CONCEPÇÃO DE EDUCAÇÃO}

De acordo com Craft (1984), a palavra educação encontra sua base etimológica nos termos latinos educare (treinar, moldar) e educere (guiar). Segundo este embasamento, pode-se compreender que a educação tem como objetivo tirar o homem de dentro de si mesmo, guiar pelo mundo e compor seu ser, sua identidade e todos os seus princípios.

A estrutura moderna da escola brasileira tem sua origem no mé- 
todo católico de educação da idade média. Período onde diversas instituições seculares surgiram, como universidade de Bolonha (1088) e universidade de Paris (1160). Tais escolas advém do intuito de ensinar a população a doutrina e formar novos clérigos. A figura do professor mestre e dos alunos sentados em fileiras, seguindo regras quase que por coerção se difundiu em boa parte do mundo ocidental, criando assim um método que abrange muitos alunos com pouco recurso (ORME, 2006).

Dentre vários conceitos presentes na educação, encontra-se a educação bancária, onde a base dessa educação está no professor como a fonte principal de transmissão do conhecimento. Um conceito que ainda repercute nos ensinamentos e em sala de aula, não em sua totalidade, porém, bastante usual e comum nas formas de ensino aprendizagens atuais.

Para Vasconcelos e Brito (2014, p. 83):

Educação bancária configura a abordagem pedagógica pela qual o educador é agente transmissor de informações e conhecimento aos educandos. Para essa concepção, o único papel do educador é o de expor/impor conhecimentos, não havendo espaço para discussão ou reflexão, sua missão é meramente informativa.

Ainda seguindo alguns conceitos relacionados à educação, percebe-se a divergência de pensamentos ou a evolução dos conceitos educacionais. Ao analisar a citação anterior, com a citação apresentada na sequência desse texto, percebe-se que inicialmente, tem-se o educador como fonte única de transmissão de conhecimento, impossibilitando debates sobre o conteúdo, e posteriormente, tem-se a visão do educador facilitador, que desenvolve o educando para buscar o seu próprio conhecimento.

Ensinar é um processo dialógico e ativo do qual educador e educando participam, fazendo com que o educador atue como facilitador e como aquele que apoia educando, possibilitando-lhe a construção de seu próprio saber (VASCONCELOS; BRITO, 2014, p. 83). 
O processo de educação segundo alguns autores, está embasado no diálogo e troca de informações, já que, compreende-se que todos tem algo a aprender e a ensinar. Partindo desse princípio, entende-se que, a contribuição educacional pode surgir por meio de debates sobre os mais variados assuntos.

Educação é antes de mais nada, ato de amor e coragem, que está embasado no diálogo, na discussão e no debate. $\mathrm{O}$ homem vive em constante aprendizado, não havendo homens "ignorantes absolutos", já que existem diferentes saberes, alguns sistematizados, outros não (VASCONCELOS; BRITO, 2014, p. 83).

Percebe-se que, a educação deve ser compreendida além da sala de aula. Ela está presente nos diálogos e discussões sociais, tornando-se assim, um processo natural de aprendizagem, devido ser adquirida numa dinâmica contínua, jamais pronta e impossível de se findar, uma vez que, nenhum indivíduo pode reter todo o conhecimento.

Segundo Durkheim (1911 apud FILLOUX, 2010, p. 15), "Cada sociedade, considerada num momento determinado de seu desenvolvimento, tem um sistema de educação que se impõe aos indivíduos". A educação se desenvolve de acordo com as mudanças ocorridas na sociedade, sendo assim, pode-se entender que, a educação vem sofrendo modificações e alterações com o passar dos anos, cabendo determinados recortes históricos, que visam o aprofundamento e compreensão dos métodos educacionais.

\section{EDUCAÇÃO E SOCIEDADE}

Desde os primórdios da educação, com sua origem cravada na criação da pólis grega, a sociedade se vê sendo moldada e conduzida pelos alicerces da educação. Serviu de arma estratégica para diversos grupos revolucionários, fora utilizada como aparato de condução e expansão, ampliando o conhecimento de mundo que temos na era pós-moderna. $\mathrm{O}$ sucesso de comunidades culturais é diretamente relacionado com sua dedicação à educação. 
Segundo Westbrook (2010, p. 44), “[...] toda educação é social, sendo, como é, uma participação, uma conquista de um modo de agir comum. Nada se ensina, nem se aprende, senão pela compreensão comum ou de um uso comum".

Percebe-se nitidamente a influência da educação também nos movimentos sociais das eras pós idade média, onde a criação de universidades cresceu vertiginosamente e o avanço tecnológico possibilitou a ampliação de novas fronteiras perante as quais a humanidade explorou e, com isso, criou uma nova maneira de pensar. O avanço dos estudos e a democratização do acesso à educação são critérios de evolução para todos os indicadores econômicos e sociais de um determinado povo.

No processo educativo, o indivíduo e o meio social são, portanto, dois fatores harmônicos e ajustados. O meio social ou o meio escolar, se bem compreendidos, devem fornecer as condições pelas quais o indivíduo liberte e realize a sua própria personalidade. Não podemos, assim, considerá-los antagônicos (WESTBROOK, 2010, p. 50).

Partindo do princípio de que o meio social e o indivíduo são diretamente interligados, sabe-se que as mudanças ocasionadas no primeiro geram forte impacto no outro. Sendo assim, compreende-se que toda e qualquer variável que seja alterada, ocasionará significativas mudanças a curto e longo prazo no modo de agir na sociedade.

Como base nisso, no século passado, pode-se presenciar o início de uma nova revolução do conhecimento. Ao passo em que a guerra fria se estendia, novas maneiras de pensar foram sendo criadas, novos estudos e o ser humano se tornou mais heterogêneo. Ao mesmo tempo, como consequência do avanço tecnológico e do crescimento populacional, a desigualdade social cresce em ritmo acelerado. É neste cenário que a educação se insere como agente transformador de toda uma sociedade (HOBSBAWM, 2001).

\section{A IMPORTÂNCIA DA EDUCAÇÃO PARA A SOCIEDADE}

Sabe-se que a educação desempenha um papel social no desen- 
volvimento do indivíduo e do desempenho da sociedade em geral. Portanto, surge a necessidade e preocupação com a qualidade do ensino, já que por muitas vezes, a educação se torna um dos únicos mecanismos de superação das condições reais para uma grande parcela de indivíduos menos favorecida na sociedade.

De acordo com a UNESCO (2013), a melhora de 0,1\% da igualdade educacional gera um aumento de $23 \%$ no salário per-capita num período de 40 anos. E com uma melhor educação, as pessoas de comunidades tradicionalmente excluídas tornam-se melhor posicionadas tendo a oportunidade de alcançar melhor qualidade de vida.

Em 2005, o tempo médio de escola da população paquistanesa era de 4,5 enquanto à população vietnamita passava em média 4,9 anos na escola. Apesar dos números serem praticamente iguais, apenas $49 \%$ da população do primeiro país frequentava a escola, em contrapartida dos 92\% do segundo país. Essa desigualdade educacional paquistanesa gerou uma queda no avanço econômico do país, enquanto o Vietnam, viu seu PIB per capita crescer de US\$2000,00 em 2005 para US\$2779,00 em 2010 (UNESCO, 2013).

O mesmo estudo demonstra que o acesso à educação é mister para o cumprimento dos 17 objetivos para transformar nosso mundo, meta estabelecida pela ONU para desenvolvimento de toda humanidade pautada nos conceitos de educação, igualdade, crescimento econômico e sustentável. A educação é indispensável para fortalecer os laços que mantém as comunidades e a sociedade unida.

\section{TECNOLOGIA NA EDUCAÇÃO}

Compreende-se que atualmente a tecnologia está presente em quase todos os campos da ciência e também no cotidiano do indivíduo. E nas escolas não se é diferente, seja no ensino infantil ou superior, percebe-se o aumento de uso da tecnologia em sala de aula.

Segundo Sousa, Moita e Carvalho (2011, p. 25):

A expressa necessidade de um maior envolvimento entre as áreas tecnológica e educacional é cada vez mais evidente. Hoje, a relação educação e tecnologia é presente em quase todos os estudos que anali- 
sam o contexto educacional.

Mesmo a tecnologia estando presente em salas de aula, é necessário que seja utilizada como eficácia na aprendizagem, já que seu uso, para Ferreira e Rosa (2012, p. 34), "É essencial que a tecnologia entre na escola não como um ornamento, mas como ferramenta eficaz de inclusão digital, proporcionando a formação de sujeitos críticos, não apenas consumidores $[\ldots]$ "...

Ao integrar a tecnologia junto à sala de aula, o educador deverá se preocupar com os objetivos do uso. A intenção é que a tecnologia possibilite o desenvolvimento de alunos proativos, capazes de desenvolver um senso crítico tornando-se o protagonista do seu aprendizado.

De acordo com Sousa, Moita e Carvalho (2011, p. 26), “A escola, para fazer cumprir sua responsabilidade social de educar e formar os novos cidadãos precisa contar com professores que estejam dispostos a captar, a entender e a utilizar as novas linguagens dos meios de informação". A função do professor no contexto educacional está relacionada ao poder de compreensão das linguagens e tecnologias utilizadas atualmente. Faz-se necessário que o educador esteja atento às tecnologias, para que possa agrega-las em sala de aula, criando desta forma, novas oportunidades de transmissão de conhecimento.

Além de disponibilizar a tecnologia na sala de aula, a escola deve se preocupar em preparar o professor para utilizá-la e demonstrar formas de uso dessa tecnologia para que se atinja a eficácia no aprendizado do educando. Uma das metodologias existentes e que contemplam o uso da tecnologia nas classes é a sala de aula invertida, que será discutida no próximo tópico de estudo.

Conforme Fantin e Rivoltella (2013, p. 181):

A inovação não é uma mudança qualquer, nem a substituição de uma ferramenta (lápis e caderno) por outra (computador). Ela tem um caráter e uma proposta conscientemente assumida para provocar melhorias na ação educativa.

Ao ocorrer a simples substituição do lápis e caderno pelo uso da tecnologia, o propósito educacional se perde, já que, ao incluir o uso de 
novas ferramentas de transmissão de conhecimento, o educador deverá ter como intenção, gerar e desenvolver novas habilidades nos alunos.

Quando é proposto o uso da tecnologia em sala de aula, surge a necessidade de pensar além da simples substituição dos meios de leitura, escrita, dentre outros, mas sim, o ideal é que essa tecnologia traga mudanças eficazes no desenvolvimento do aluno. Podendo ser o desenvolvimento de pro-atividade, senso crítico, autonomia, etc.

"A evolução tecnológica não se restringe aos novos usos dos equipamentos e/ou produtos, mas ao comportamento dos indivíduos que interferem/repercutem nas sociedades, intermediados pelos equipamentos" (FANTIN; RIVOLTELLA, 2013, p. 181). As mudanças nos meios de comunicação ocasionam certo impacto no comportamento da sociedade em geral, seja por meio da maior facilidade de comunicação ou por meio de informações mais rápidas. É certo que, a partir do momento que o indivíduo tem acesso a algumas ferramentas tecnológicas, o comportamento individual altera aos poucos, seja a sua formação de opinião ou até mesmo a influência que ocorre em suas crenças.

$\mathrm{O}$ individuo interage com a tecnologia a todo instante, conseguindo obter informações sobre os mais variados assuntos por meio de apenas um "clique". O acesso a internet, os dispositivos móveis, tablets, dentre outras tecnologias, permitem que a compreensão e entendimento das informações seja quase imediata.

Para Sousa, Moita e Carvalho (2011, p. 27):

Enquanto as crianças e jovens interagem com mais informações audiovisuais e meios eletrônicos do que com mídias impressas, vivendo em um mundo permeado pelas tecnologias digitais, seus professores foram formados para ministrar um ensino baseado em técnicas pedagógicas, conteúdos e materiais convencionais. Muitos educadores acabam apenas reproduzindo os modelos tradicionais de ensino quando propõem atividades com objetos digitais em sala de aula, desconsiderando a transição do paradigma aprendizagem/sala de aula/escola para aprendizagem/redes sociais/sociedade do conhecimento.

Devido à interação do aluno com a tecnologia, o mesmo obtém 
de forma rápida o aprendizado teórico. Portanto, o estudante não se vê mais refém de aulas conceituais, se tornando independente, já que pode buscar a qualquer momento vídeos em diversas plataformas, artigos, revistas e livros eletrônicos que possibilitam o entendimento teórico de assuntos necessários. Dessa facilidade de busca por conteúdos surge a oportunidade de interagir de novas formas com esse aluno, possibilitando assim, novos métodos de ensino, como as metodologias ativas.

\section{SALA DE AULA INVERTIDA}

Devido a todo esse contexto de modificações na sociedade e da importância que a educação exerce nos grupos sociais, surge a tecnologia como uma opção de adequação para a educação. Uma das metodologias encontradas para fazer a junção dessas variáveis é a sala de aula invertida ou "flipped classroom".

De acordo com Suhr (2016), flipped classroom ou sala de aula invertida é um método que foi desenvolvido pelos autores Bergmann e Sams, a partir da experiência por eles estudadas em escolas de nível médio nos Estados Unidos.

Os autores Bergmann e Sams (2018, p. 11), conceituam sala de aula como sendo "o que basicamente é feito em sala de aula, agora é executado em casa, e o que tradicionalmente é feito como trabalho de casa, agora é realizado em sala de aula".

Nessa metodologia, o professor disponibiliza conteúdos a serem estudados antes da aula, geralmente em formato digital. Conforme Ramal (2015 apud SCHMITZ, 2016, p. 38), "o aluno estuda os conceitos básicos antes da aula, com vídeo, textos, arquivos de áudio, games e outros recursos".

A sala de aula invertida é uma modalidade de e-learning na qual o conteúdo e as instruções são estudados on-line antes de o aluno frequentar a sala de aula, que agora passa a ser o local para trabalhar os conteúdos já estudados realizando atividades práticas como resolução de problemas e projetos, discussão em grupo, laboratórios etc. (VALENTE, 2014, p. 85). 
Após essa disponibilização de conteúdos online, conforme critérios definidos pelo professor da disciplina, surge o papel do aluno e sua pró-atividade nos estudos dos conteúdos disponibilizados pelo professor. "Cabe ao aluno realizar o estudo prévio dos conteúdos disponibilizados e preparar-se para os encontros presenciais, nos quais devem ocorrer atividades de discussão [...]" (SUHR, 2016, p. 06).

Talvez, uma das dificuldades da implementação da sala de aula invertida, ainda esteja na produção e disponibilização dos conteúdos para os alunos, já que demandará um maior tempo na preparação desses materiais e também, é necessário que tanto professor como aluno tenha acesso à tecnologia. "Os aspectos fundamentais da implantação da sala de aula invertida são a produção de material para o aluno trabalhar on-line e o planejamento das atividades a serem realizadas na sala de aula presencial" (VALENTE, 2014, p. 85).

As autoras Rodrigues, Spinasse e Vosgerau em suas pesquisas, fizeram um levantamento dos motivos para se implantar a sala de aula invertida. Pode-se observá-los no quadro exposto abaixo:

Quadro 1: Motivos para a implementação da sala de aula invertida

\begin{tabular}{|l|}
\hline \multicolumn{1}{|c|}{ Motivos para implementação } \\
\hline Fornecimento de instrução teórica aos alunos que faltaram na aula. \\
Maior aproveitamento do tempo de aula. \\
Relevância dos alunos estarem ativos em sala de aula. \\
Avanço tecnológico. \\
Problemas financeiros. \\
Melhor desenvolvimento dos alunos. \\
\hline
\end{tabular}
Fonte: Rodrigues, Spinasse e Vosgerau (2014, p. 39286)

Nota-se no quadro acima que, a implementação da sala de aula invertida pode contribuir para resolução de algumas situações corriqueiras em salas de aula. Como por exemplo, em casos que o estudante por algum motivo perde o conteúdo desenvolvido em classe, o mesmo terá a sua disposição, mais uma ferramenta de aprendizagem, amenizando assim a baixa compreensão do assunto.

Devido o conteúdo teórico ser disponibilizado por meio de mídia, 
antes mesmo de a aula ocorrer, entende-se também como motivação para aplicabilidade da sala de aula invertida, o fato de o aluno poder assistir esse conteúdo várias vezes, até a absorção total da teoria. Assim, o papel do professor em sala de aula, ocorre com maior facilidade no sentido de desenvolver debates de ideias.

Ainda para as mesmas autoras, pode-se destacar o papel do aluno na sala de aula invertida. Ao inserir-se nessa metodologia, o aluno recebe uma parcela de responsabilidade sobre seus estudos, já que parte do seu aprendizado dependerá do tempo dedicado em casa, antes mesmo do horário de aula.

Os autores Bermann e Sams (2018), ainda apresentam diferentes motivos para a inversão da sala de aula, sendo eles: a inversão fala a língua dos estudantes de hoje, que vivem conectados à internet e a vários recursos digitais; a inversão ajuda os estudantes ocupados, que alternam seu tempo entre várias atividades. Como o conteúdo é transmitidos por meio de vídeo, o aluno poderá avançar de acordo com o seu ritmo; a inversão ajuda os estudantes que enfrentam dificuldades; a inversão ajuda alunos com diferentes habilidades a se superarem; a inversão cria condições para que os alunos pausem e rebobinem o professor; a inversão intensifica a interação aluno-professor; a inversão possibilita que os professores conheçam melhor seus alunos; a inversão aumenta a interação aluno-aluno, já que os estudantes passam a se ajudarem ao invés de depender unicamente do professor; a inversão permite a verdadeira diferenciação, como o conteúdo teórico já não pertence mais a sala de aula, o professor poderá atender de forma individualizada os estudantes enquanto os mesmos executam as atividades; a inversão muda o gerenciamento da sala de aula, onde o estudante indisciplinado passa a executar atividades práticas em sala de aula, ou passa a ser ignorado pelos demais alunos que se preocupam em realizar suas atividades práticas em sala de aula; a inversão muda a maneira como conversamos com os pais, onde deixa-se de lado questionamentos como "o filho está se comportando em sala de aula?" e passa-se a responder questionamentos como "os alunos estão aprendendo?"; a inversão educa os pais, onde os pais podem assistir e debater os assuntos apresentados na aula online, junto com os seus filhos; a inversão torna a aula mais transparente, onde pais e sociedade podem ter acesso a essas aulas; a inversão é uma ótima ferramenta na 
ausência de professores; e a inversão pode induzir o programa reverso de aprendizagem para o domínio.

Segundo as autoras Rodrigues, Spinasse e Vosgerau (2014), o papel do aluno na sala de aula invertida se concentra em três aspectos, sendo eles, assistir as aulas disponibilizadas antes mesmo do encontro presencial, envolver-se nas atividades ocorridas em sala de aula, e ser responsável pelo desenvolvimento da sua aprendizagem.

É importante compreender que na sala de aula invertida o tempo de aula segue uma nova estrutura, conforme exposto na tabela abaixo.

Tabela 1: Comparação do uso do tempo nas salas de aula tradicional e invertida

\begin{tabular}{|c|c|c|c|}
\hline \multicolumn{2}{|c|}{ Sala de aula tradicional } & \multicolumn{2}{c|}{ Sala de aula invertida } \\
\hline Atividade & Tempo & Atividade & Tempo \\
\hline $\begin{array}{c}\text { Atividade de } \\
\text { aquecimento }\end{array}$ & 5 minutos & $\begin{array}{c}\text { Atividade de } \\
\text { aquecimento }\end{array}$ & 5 minutos \\
\hline $\begin{array}{c}\text { Repasse do dever de } \\
\text { casa da noite anterior }\end{array}$ & 20 minutos & $\begin{array}{c}\text { Perguntas e } \\
\text { respostas sobre o } \\
\text { vídeo }\end{array}$ & 10 minutos \\
\hline $\begin{array}{c}\text { Preleção de novo } \\
\text { conteúdo }\end{array}$ & $\begin{array}{c}\text { Prática orientada } \\
\text { e independente e/ } \\
\text { ou atividade de } \\
\text { laboratório }\end{array}$ & 75 minutos \\
\hline $\begin{array}{c}\text { Prática orientada } \\
\text { e independente e/ } \\
\text { ou atividade de } \\
\text { laboratório }\end{array}$ & $\begin{array}{c}20-35 \\
\text { minutos }\end{array}$ & & \\
\hline
\end{tabular}

Fonte: Bergmann e Sams (2018, p. 13)

A disponibilização antecipada das aulas pode ocorrer pelo uso de vídeo-aulas, onde entende-se como vídeo-aulas a explanação por meio de vídeos dos temas de estudos, com intuito a compor o saber do aluno e preparar à aula. Geralmente as vídeo-aulas são previamente disponibilizadas em plataformas digitais, de acordo com a preferência do professor.

A partir do momento em que o aluno assiste as vídeo-aulas antes 
de entrar em sala, possibilita que o mesmo tenha condições melhores de participar ativamente sobre debates e discussões, como também, pode contribuir para que haja um melhor desenvolvimento das atividades realizadas em sala de aula, já que o estudante teve um conhecimento prévio do assunto e um tempo maior de reflexão, podendo dessa forma, estar mais seguro para opinar ou realizar atividades de determinados assuntos.

Por meio da sala de aula invertida o aluno se torna protagonista do seu aprendizado e desenvolvimento acadêmico, contudo, o professor continua com sua importância na formação desse individuo, pois, será ele o mediador que possibilitará o desenvolvimento individual desse estudante.

Portanto, além das responsabilidades do aluno, na sala de aula invertida o professor também recebe um novo papel que difere um pouco da metodologia das aulas expositivas. Na sala de aula invertida, o professor, torna-se, de certa forma, um mediador do conteúdo, não sendo mais o detentor de todo conhecimento.

Para as autoras Rodrigues, Spinasse e Vosgerau (2014), o professor tem a função de subsidiar os caminhos que permitem a construção do conhecimento. Neste contexto ele é o facilitador e incentivador de debates acadêmicos, um mediador e auxiliador dessas discussões, onde deve, inclusive, ser um ouvinte assíduo das ideias discutidas em sala de aula.

Mediante as funções do professor em sala de aula, é possível compreender que na aplicação da sala de aula invertida surgem benefícios e desafios ao docente. Sendo assim, pode-se observar os benefícios e desafios encontrados pelos professores e alunos, conforme apresentado na tabela a seguir. 
Quadro 2: Benefícios e desafios da sala de aula invertida

\begin{tabular}{|c|c|}
\hline ícios & Desafios \\
\hline $\begin{array}{l}\text { Substituição da aprendizagem passiva, com aulas } \\
\text { participativas. } \\
\text { Conteúdo permanentemente disponibilizado ao } \\
\text { estudante. } \\
\text { O professor pode apresentar o conteúdo uma úni- } \\
\text { ca vez em vídeo. } \\
\text { Explicação de todo o conteúdo planejado em me- } \\
\text { nos tempo. } \\
\text { Ao gravar o vídeo, o professor passa a refletir so- } \\
\text { bre sua aula. } \\
\text { Aumento da interação entre aluno-aluno e aluno- } \\
\text {-professor. } \\
\text { Os professores dispõem de tempo para trabalhar } \\
\text { com os alunos individualmente. } \\
\text { Progresso dos alunos nos testes de avaliação } \\
\text { Envolvimento dos pais na educação dos filhos. } \\
\text { Aumento da responsabilidade dos estudantes. } \\
\text { O aluno trabalha em seu próprio ritmo e estilo. } \\
\text { Promove o desenvolvimento de habilidades de } \\
\text { comunicação, trabalho em equipe e colaboração } \\
\text { de ideias. } \\
\text { Permite ao aluno colocar o seu aprendizado em } \\
\text { prática. }\end{array}$ & $\begin{array}{l}\text { Maior tempo para a } \\
\text { preparação da aula. } \\
\text { Os alunos preci- } \\
\text { sam ser preparados } \\
\text { e orientados para o } \\
\text { desenvolvimento } \\
\text { da aula. } \\
\text { Resistência dos } \\
\text { alunos ao novo mé- } \\
\text { todo. } \\
\text { Distribuição dos } \\
\text { materiais em vídeo. } \\
\text { Demanda que a } \\
\text { abordagem pode } \\
\text { fazer nos computa- } \\
\text { dores de casa. } \\
\text { Os alunos não as- } \\
\text { sistirem os vídeos } \\
\text { em casa. } \\
\text { As condições nas } \\
\text { quais os alunos as- } \\
\text { sistem os vídeos. }\end{array}$ \\
\hline
\end{tabular}

Fonte: Rodrigues, Spinasse e Vosgerau (2014, p. 39287)

Por meio dos estudos existentes e com base nas informações destacadas pelas autoras Rodrigues, Spinasse e Vosgerau (2014), percebeu-se que a sala de aula invertida possibilita o uso de tecnologias e gera aprendizagem eficaz aos alunos. Além do uso de ferramentas tecnológicas, a sala de aula invertida, pode gerar ao educando, a possibilidade de desenvolver seu senso crítico, pró-atividade, melhoria na comunicação, melhor interação com os colegas de sala e um desenvolvimento de autonomia em seus estudos.

Por ser uma metodologia ainda não difundida em grande escala, 
muitas vezes pode gerar estranheza ou desconforto, tanto no educador como no educando, porém, pode-se considerar essa negação quanto à metodologia, como um processo de adaptação.

\section{CONSIDERAÇÕES FINAIS}

Após a realização do levantamento bibliográfico compreendeu-se que, a sala de aula invertida não tem o dever de substituir o ensino tradicional, e suas aulas expositivas, mas sim, surge como possibilidade de ampliação metodológica, outras ferramentas que podem ser aplicadas e utilizadas para desenvolver habilidades e interesse nos alunos para o estudo.

Pôde-se perceber que ainda há uma limitação em relação à disponibilização de materiais literários sobre sala de aula invertida. Talvez, por ser um assunto relativamente novo no Brasil, poucos são os artigos científicos disponíveis para pesquisa. Não obstante, a aplicabilidade dessa prática ainda é pouco usual no ensino brasileiro.

Observou-se que a aplicabilidade da sala de aula invertida, gera benefícios ao ensino, entretanto, ainda existem certas preocupações perante o seu uso, já que o professor poderá esbarrar em limitações relacionadas à estrutura escolar e social do aluno. Como o exemplo dessa limitação, pode-se citar a limitação do acesso a internet a toda a população.

Sabe-se que, o uso da sala de aula invertida como ferramenta educacional, pode sim despertar alunos proativos e detentores da capacidade de desenvolver o seu próprio aprendizado, por vezes, tirando a visão de que a responsabilidade do aprendizado está apenas e totalmente nas mãos dos educadores.

Percebeu-se também que o fator cultural ainda é uma barreira a ser vencida. Tanto os educadores, como os alunos, ainda precisam ter um contato maior com a ferramenta, para melhor compreensão do desenvolvimento da mesma, já que, por se tratar de uma ferramenta relativamente nova, gera certa insegurança ou desconforto.

Mesmo com uma grande parcela da sociedade brasileira tendo acesso a internet e demais dispositivos tecnológicos, ainda existe a preocupação em relação à exclusão de alunos que não tenham acesso a essas ferramentas tecnológicas, ao se utilizar da sala de aula como metodologia. 
É certo que aos poucos a inclusão da tecnologia está se fazendo presente em sala de aula, tanto por uma necessidade de despertar um maior interesse nos alunos, mas também, como a oportunidade de inovação que os professores encontram para desenvolver os conteúdos. Contudo, ainda existe a necessidade de um estudo mais detalhado e aprofundado, não apenas quanto à sala de aula invertida, mas também em relação à aplicabilidade e benefícios em geral desses meios tecnológicos.

Cabe aqui ressaltar que, a sala de aula invertida tem como função possibilitar mais uma ferramenta de ensino ao professor, entretanto, não tem como função desconsiderar as demais formas e métodos de ensino. Para tanto, a mesma deve ser utilizada quando surge a intenção de desenvolver características especificas no estudante, como por exemplo, a pro atividade e senso critico.

Por meio dessas constatações, notou-se a possibilidade e a necessidade do desenvolvimento de estudos relacionados a sala de aula invertida, com a intenção de um aprofundamento melhor e principalmente o estudo e analise prática em relação ao uso de determinados meios tecnológicos. Para que assim, possa-se compreender melhor os reais impactos tanto positivos como negativos, além de contribuir cientificamente com os métodos educacionais.

\section{REFERÊNCIAS}

BERMANN, J.; SAMS, A. Sala de aula invertida: uma metodologia ativa de aprendizagem. Rio de Janeiro: LTC, 2018.

CERVO, A. L.; BERVIAN, P. A.; SILVA, R. Metodologia científica. 6. ed. São Paulo: Pearson, 2007.

CRAFT, M. Education and Cultural Pluralism. London: Falmer Press. 1984.

FANTIN, M.; RIVOLTELlA, P. C. (org.). Cultura digital e escola: pesquisa e formação de professores. Campinas: Papirus, 2013.

FAVA, R. O ensino na sociedade digital. Disponível em http://www. semesp.org.br/si te/noticias/o-ensino-na-sociedade-digital/. Acesso em: 
21 out. 2017.

FERREIRA, A. T. B.; ROSA, E. C. S. (org.). O fazer cotidiano na sala de aula: a organização do trabalho pedagógico no ensino da língua materna. Belo Horizonte: Autentica, 2012.

FILLOUX, J. C. Émile Durkheim. Recife: Massangana, 2010. Disponível em: http://livros01.livrosgratis.com.br/me4657.pdf. Acesso em: 17 fev. 2018 .

GERHARDT, T. E.; SILVEIRA, D. T. (org.). Métodos de pesquisa. Porto Alegre: UFRGS, 2009.

HOBSBAWM, E. J. Era dos extremos: o breve século XX 1914-1991. São Paulo: Companhia das Letras, 2001.

KÖCHE, J. C. Fundamentos de metodologia científica: teoria da ciência e iniciação à pesquisa. 34. ed. Petrópolis: Vozes, 2015.

ORME, N. Medieval Schools. New Haven: Yale University Press. 2006.

RODRIGUES, C. S.; SPINASSE, J. F.; VOSGERAU, D. S. R. Sala de aula invertida: uma revisão sistemática. In: EDUCERE CONGRESSO NACIONAL DE EDUCAÇÃO, 2015, Curitiba. Educere Congresso Nacional de Educação. Curitiba: Editora Champagnat. v. 1. p. 3928339295.

SCHMITZ, E. X. S. Sala de aula invertida: uma abordagem para combinar metodologias ativas e engajar alunos no processo de ensinoaprendizagem. 2016. 185 f. Dissertação (mestrado) - Universidade Federal de Santa Maria, Santa Maria, 2016.

SOUSA, R. P.; MOITA, F. M. C. S. C.; CARVALHO, A. B. G. (org.). Tecnologias digitais na educação. Campina Grande: EDUEPB, 2011.

SOUZA, M. V. Choques de gerações. Disponível em: http://www. revistaeducacao.com.br/choque-de-geracoes-2/. Acesso em: 21 out. 2017. 
SUHR, I. R. F. Desafios no uso da sala de aula invertida no ensino superior. Revista Transmutare, Curitiba, v. 1, n. 1, p. 4-21, jan./jun. 2016. Disponível em: https://perio dicos.utfpr.edu.br/rtr. Acesso em: 11 nov. 2017.

UNESCO. Education transforms lives. Paris: United Nations Educational, Scientific and Cultural Organization, 2013. Disponível em: http://unesdoc.unesco.org/images/0022/002231/223115E.pdf. Acesso em: 17 nov. 2017.

VALENTE, J. A. Blended learning e as mudanças no ensino superior: a proposta da sala de aula invertida. Educar em Revista. Curitiba, n. spe4, p. 79-97, 2014. Disponível em: http://www.scielo.br/scielo. php?script=sci_arttext\&pid=S0104-40602014000800079\&lng=en\&nrm =iso. Acesso em: 4 nov. 2017.

VASCONCElOS, M. L. M. C.; BRITO, R. H. P. de. Conceitos de educação em Paulo Freire. 6. ed. Petrópolis: Vozes, 2014.

WESTBROOK, R. B. (org). John Dewey. Recife: Massangana, 2010. Disponível em: http:/www.dominiopublico.gov.br/download/texto/ me4677.pdf. Acesso em: 19 jan. 2018.

Recebido em: 06/11/18 Aprovado em: 31/08/19 